\title{
CrimRxiv
}

\section{Review 3 of "Pennsylvania}

Juvenile Probation

Departments in the Wake

of the Luzerne County

Scandal: What Has

Changed?"

\section{Youngki Woo}

Published on: Mar 01, 2021

DOI: $10.21428 / c b 6 a b 371.9124 b 179$

License: Creative Commons Attribution 4.0 International License (CC-BY 4.0). 
Vote: Reject

[For votes to count, referees must reasonably explain why they voted as they did. Thus, please explain your vote. If you voted to publish pending minor changes, specify each change, why it is needed, and, possibly, how it should/could be done.]

Literature review is not well connected to the purpose of the study. The main purpose of the current study is to determine how juvenile probation practices have changed since the scandal, but the literature review discussed consequences of involvement of the juvenile justice system and discretion of juvenile probation and the court.

Regarding methods, it is unclear whether they examine the impact of the scandal on their policies and practices as the juvenile probation officer. For example, I don't find whether the author(s) asked about the recommendations by the Interbranch Commission to the participant. In addition, the author(s) should have asked how their practices and policies have changed prior to and following the scandal. But I don't find any description of this. Though some practices and programs that the department is currently using are delineated, it is unclear whether these practices and programs have changed since the scandal.

Though the author(s) mentioned as a limitation of the study, sample size (16 out of 62 ) is a quite small that may not be able to examine the study purpose as this research aims to assess the impact of the scandal on the juvenile probation departments across the state. I suspect that the current results may not be unbiased and generalizable. Indeed, I don't find any information on the IRB for the data collection.

Discussion and conclusion section is too short that the author(s) does not adequately address and discuss the issue of scandal and corruption between the court and the juvenile probation department. In addition to that, the discussion section does not really advance substantive understanding of the impacts of the scandal. As it stands currently, the implications of the study are very limited, making a small contribution to the current practices of the juvenile probation in PA.

There are many errors in the references and they are not written by the right format. Overall, a thorough editing from beginning to end is needed 